07

\title{
Разработка методов жидкостного травления разделительной меза-структуры при создании каскадных солнечных элементов
}

\author{
(C) А.В. Малевская, Н.Д. Ильинская, В.М. Андреев \\ Физико-технический институт им. А.Ф. Иофффе РАН, Санкт-Петербург, Россия \\ E-mail: amalevskaya@mail.ioffe.ru
}

Поступило в Редакцию 28 июня 2019г.

В окончательной редакции 19 июля 2019г.

Принято к публикации 16 сентября 2019 г.

\begin{abstract}
Выполнены исследования постростовой технологии изготовления каскадных солнечных элементов на основе гетероструктуры GaInP/GaInAs/Ge. Исследованы методы жидкостного химического и электрохимического травления слоев гетероструктуры. Разработана технология создания разделительной меза-структуры, достигнуто улучшение качества поверхности и профиля боковой стенки мезы для гетероструктур с разным составом слоев.
\end{abstract}

Ключевые слова: каскадный солнечный элемент, гетероструктура, травление, меза-структура.

DOI: 10.21883/PJTF.2019.24.48795.17953

Наибольший интерес для солнечной электроэнергетики представляют кремниевые солнечные элементы и каскадные солнечные элементы (КСЭ) на основе гетероструктур $\mathrm{A}_{3} \mathrm{~B}_{5}$ [1]. Рекордные значения КПД $46 \%$ получены в для четырехкаскадных КСЭ $\mathrm{A}_{3} \mathrm{~B}_{5}$ при 500-кратном концентрировании солнечного излучения (AM 1.5) [2]. Задачей дальнейшего развития солнечной электроэнергетики на основе КСЭ является снижение себестоимости получаемой „солнечной“ электроэнергии путем разработки технологии изготовления КСЭ, усовершенствования их конструкции, увеличения масштабов производства и повышения эффективности преобразования солнечного излучения [3]. За счет совершенствования постростовой технологии можно снизить затраты без потери КПД КСЭ.

Постростовая технология создания КСЭ включает несколько технологических операций: формирование антиотражающего покрытия, омических контактов и разделительной меза-структуры $[4,5]$. В настоящей работе проведены исследования и разработки технологии формирования разделительной мезы на основе гетероструктуры $\mathrm{GaInP} / \mathrm{GaInAs} / \mathrm{Ge}$ на подложке германия p-типа проводимости. Одними из самых дешевых и производительных методов создания разделительной мезаструктуры до сих пор являются методы жидкостного химического травления. Однако полупроводниковая многослойная гетероструктура состоит из набора тонких слоев разного состава, обладающих различными физикохимическими свойствами, что создает определенные сложности в процессе их травления. Для решения поставленной задачи проведено исследование технологии одностадийного и двухстадийного жидкостного травления разделительной меза-структуры путем комбинированного химического и электрохимического травления для разных по составу многослойных гетероструктур. Исследован набор травителей на основе бромистово- дородной кислоты, бихромата калия, водного раствора сернокислого церия, исследованы слабощелочные электролиты с добавлением глицерина.

Формирование разделительной меза-структуры проводится с использованием метода фотолитографии: рабочая область КСЭ закрывается маской фоторезиста, выполняется термическая обработка маски для увеличения химической стойкости, затем осуществляются травление структуры и пассивация боковой поверхности мезы диэлектриком (например, $\mathrm{Si}_{3} \mathrm{~N}_{4}$ ).

Разработка и модификация состава слоев гетероструктуры приводят к необходимости тщательной проработки и исследования метода жидкостного химического травления при работе с новой структурой. На стадии разработки постростовой технологии можно использовать метод травления структуры и германиевой подложки в два технологических этапа. На первом этапе осуществляется травление слоев гетероструктуры GaInP/GaInAs селективно до германиевой подложки через первую маску фоторезиста. На втором этапе проводится травление германиевой подложки через вторую маску фоторезиста с шириной мезы на $15-30 \mu \mathrm{m}$ больше, при этом боковая поверхность потравленных слоев гетероструктуры GaInP/GaInAs остается закрытой маской фоторезиста (рис. 1,a). Этот метод приводит к увеличению количества технологических операций, однако он позволяет проводить постростовую обработку для гетероструктур с различным составом слоев на начальном этапе разработки технологии.

Для увеличения производительности технологического процесса создания меза-структуры нами был разработан метод двухстадийного последовательного травления слоев гетероструктуры и германиевой подложки с использованием одной маски фоторезиста.

Для травления слоев многослойной гетероструктуры GaInP/GaInAs разработан метод жидкостного химиче- 


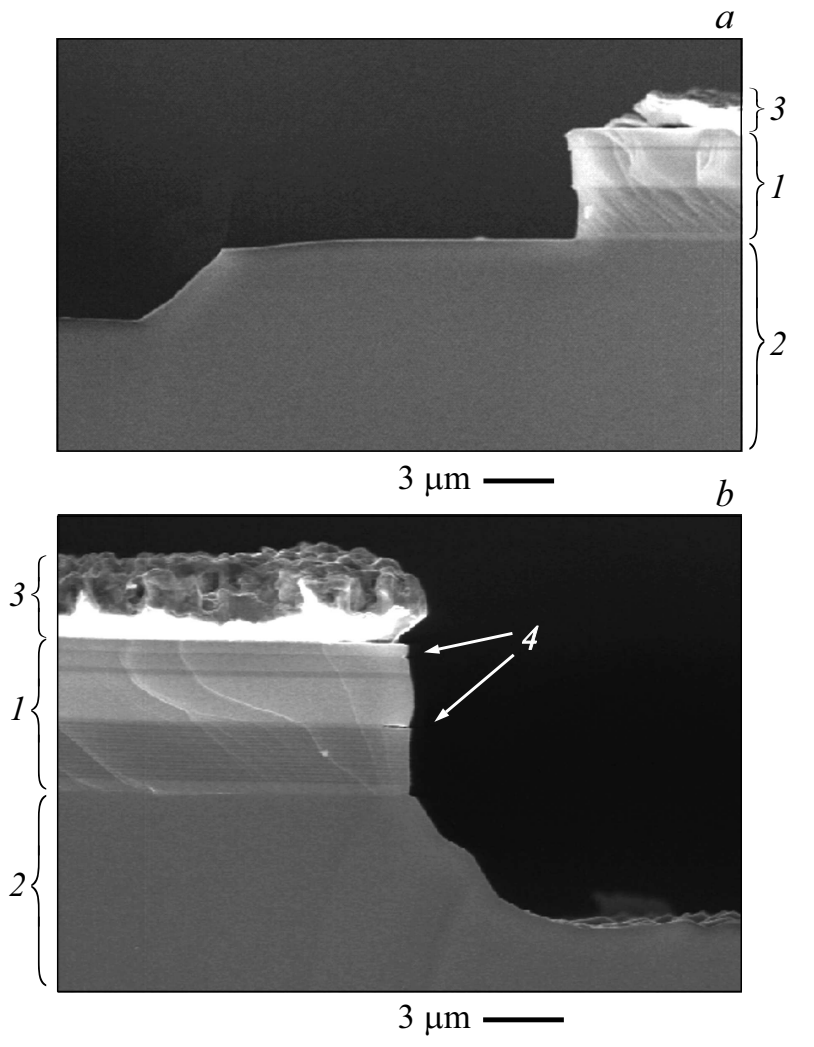

Рис. 1. Микрофотографии меза-структуры, полученные с помощью сканирующего электронного микроскопа (СЭМ) после проведения жидкостного химического травления в два технологических этапа $(a)$ и после проведения двухстадийного жидкостного химического травления с использованием сильно разбавленного травителя $\left(\mathrm{HBr}: \mathrm{H}_{2} \mathrm{O}_{2}: \mathrm{H}_{2} \mathrm{O}\right)(b) .1$ - гетероструктура III-V, 2 - германиевая подложка, 3 - омический контакт, 4 - протравы по слоям гетероструктуры III-V.

ского травления в травителе на основе бихромата калия и бромистоводородной кислоты следующего состава: $\mathrm{K}_{2} \mathrm{Cr}_{2} \mathrm{O}_{7}(80-110 \mathrm{~g} / \mathrm{l}), \mathrm{HBr}(80-110 \mathrm{~g} / \mathrm{l})$. Данный состав травителя обеспечивает высокую стойкость маски фоторезиста и оптимальную скорость травления (порядка $0.5 \mu \mathrm{m} / \mathrm{min}$ ) для всех слоев гетероструктуры селективно до германиевой подложки. За счет равномерного травления структуры не происходит образования уступов и протравов по отдельным слоям, что обеспечивает создание ровной боковой поверхности мезы.

Характерные травители для германиевой подложки не могут использоваться для проведения локального травления, так как отдельные слои гетероструктуры $\mathrm{A}_{3} \mathrm{~B}_{5}$ травятся в них с разной скоростью, образуются протравы по боковой стенке мезы, в том числе из-за низкой стойкости маски фоторезиста. Нами разработана технология жидкостного химического травления германия в смеси на основе водного раствора сернокислого церия и серной кислоты следующего состава: $\mathrm{Ce}\left(\mathrm{SO}_{4}\right)_{2} \cdot 4 \mathrm{H}_{2} \mathrm{O}$ (25-35 g/1), $\mathrm{H}_{2} \mathrm{SO}_{4}$ (3.5-4.5 g/l). При использовании данного травителя не происходит раство- рения слоев гетероструктуры III-V, и боковая стенка мезы не изменяется. Однако из-за низкой растворимости продуктов реакции в воде при проведении промывки после травления соли церия могут выпадать в осадок на поверхности меза-структуры, что приводит к дополнительным утечкам тока $p-n$-переходов. Проведены исследования метода травления германиевой подложки в сильно разбавленном травителе на основе бромистоводородной кислоты и перекиси водорода следующего состава: $\mathrm{HBr}(8-12 \mathrm{~g} / 1), \mathrm{H}_{2} \mathrm{O}_{2}(0.9-1.1 \mathrm{~g} / 1)$ [6] (рис. 1,b). Недостатками метода являются низкая скорость травления (порядка $0.05 \mu \mathrm{m} / \mathrm{min}$ ); чувствительность травителя к наличию примеси, в частности металлов; образование протравов по отдельным слоям гетероструктуры.

Для увеличения качества и надежности процесса формирования разделительной меза-структуры проведена разработка травления германиевой подложки методом электрохимического травления в слабощелочном электролите с добавлением глицерина следующего состава: глицерин $(30-50 \mathrm{~g} / 1), \mathrm{KOH}(1-4 \mathrm{~g} / 1)$ [7]. При низких плотностях тока $\left(J<3 \cdot 10^{-3} \mathrm{~A} / \mathrm{cm}^{2}\right)$ скорость анодного растворения не зависит от типа проводимости германия. На практике растворение германия в данном электролите следует проводить при больших плотностях тока $\left(J=7 \cdot 10^{-3}-10^{-2} \mathrm{~A} / \mathrm{cm}^{2}\right)$, и тогда скорость анодного растворения начинает зависеть от поверхностной концентрации дырок [8]. Анодное растворение германия начинается при потенциале $0.15 \mathrm{~V}$ и в щелочной среде протекает по реакции

$$
\mathrm{Ge}+6 \mathrm{OH}^{-}+m e^{-} \rightarrow \mathrm{GeO}_{3}^{2-}+3 \mathrm{H}_{2} \mathrm{O}+(4-m) e^{-} .
$$

Проведено изучение различных режимов электрохимического травления. Исследования показали, что получение зеркальной поверхности, оптимальной скорости травления $(0.5-1 \mu \mathrm{m} / \mathrm{min})$, минимальной области бокового травления германия под структуру III-V $(0.2-0.5 \mu \mathrm{m}$ при глубине травления $1 \mu \mathrm{m})$ и устойчивости маски фоторезиста осуществляется при проведении

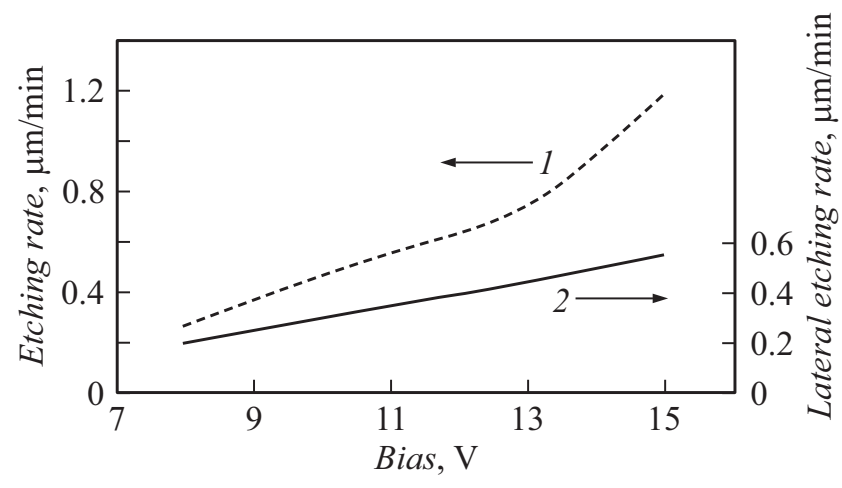

Рис. 2. Влияние режимов электрохимического травления германия на форму профиля меза-структуры. 1 - зависимость скорости травления германия от напряжения, 2 - зависимость скорости бокового травления германия от напряжения. 


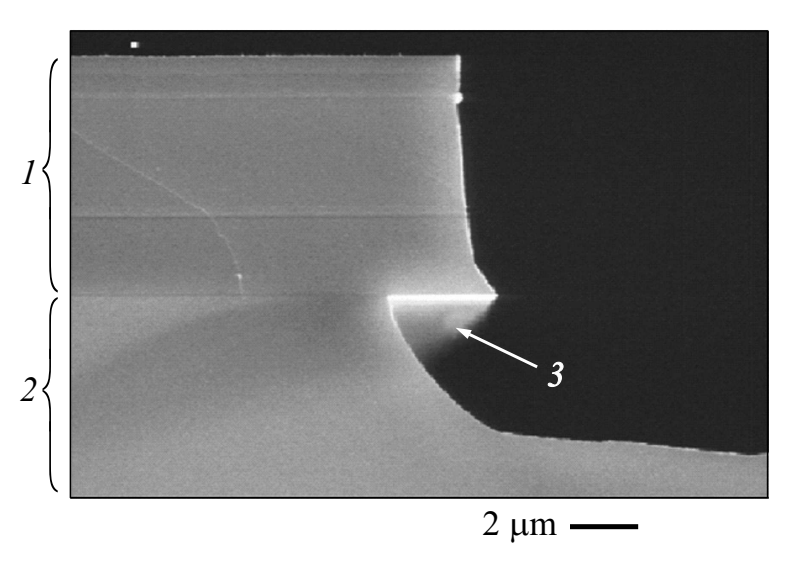

Рис. 3. СЭМ-микрофотография меза-структуры после проведения двухстадийного разделительного жидкостного химического $\left(\mathrm{K}_{2} \mathrm{Cr}_{2} \mathrm{O}_{7}: \mathrm{HBr}: \mathrm{H}_{2} \mathrm{O}\right)$ и электрохимического травления (глицерин: $\mathrm{KOH}: \mathrm{H}_{2} \mathrm{O}$ ). 1 - гетероструктура III-V, 2 - германиевая подложка, 3 - боковое травление германия.

травления в следующих режимах: напряжение $10-15 \mathrm{~V}$, температура $19-23^{\circ} \mathrm{C}$ (рис. 2). При дальнейшем увеличении напряжения более $19 \mathrm{~V}$ снижается стойкость маски фоторезиста и увеличивается скорость бокового травления германия под структуру III-V. Характер и скорость растворения слабо зависят от площади, что позволяет проводить технологический процесс на образцах большой площади согласно разработанным режимам.

Преимуществом данного метода является высокое качество поверхности травления германиевой подложки. Анодное травление проводится в слабощелочном растворе и не оказывает влияния на боковую стенку мезы, что позволяет избежать протравов по отдельным слоям гетероструктуры III-V. Недостатком метода является образование уступа, зависящего от глубины травления германия (рис. 3), что оказывает влияние на выбор метода пассивации мезы диэлектрическим покрытием при использовании метода плазмоактивированного пиролиза. Большой опыт использования данной технологии формирования разделительной мезаструктуры при изготовлении КСЭ показал высокую производительность, надежность и воспроизводимость метода.

Проведены исследования постростовой технологии формирования разделительной меза-структуры при изготовлении КСЭ. Исследованы различные методы травления многослойных гетероструктур на основе $\mathrm{GaInP} / \mathrm{GaInAs} / \mathrm{Ge}$ и разработана технология создания меза-структуры с ровной боковой поверхностью путем комбинирования травителей разного состава. Данное исследование позволяет оптимизировать постростовую технологию для гетероструктур с различным составом слоев, увеличить надежность пассивации поверхности мезы, снизить ток утечки $p-n$-переходов и увеличить КПД каскадных солнечных элементов.

\section{Финансирование работы}

Исследование выполнено за счет гранта Российского научного фонда (проект № 17-79-30035).

\section{Конфликт интересов}

Авторы заявляют, что у них нет конфликта интересов.

\section{Список литературы}

[1] Alferov Zh.I., Andreev V.M., Rumyantsev V.D. // Concentrator photovoltaics / Eds A. Luque, V. Andreev. Springer Ser. in Optical Sciences. 2007. V. 130. P. 25-50.

[2] Green M.A., Hishikawa Y., Dunlop E.D., Levi D.H., HohlEbinger J., Yoshita M., Ho-Baillie A.W.Y. // Progr. Photovolt.: Res. Appl. 2018. V. 27. P. 3-12. DOI: 10.1002/pip.3102

[3] Apostoleris H., Stefancich M., Chiesa M. Concentrating photovoltaics (CPV): the path ahead. 1st ed. Cham: Springer International Publ., 2018. $68 \mathrm{p}$.

[4] Schwartz G.C., Srikrishnan K.V. Hadbook of semiconductor technology. 2nd ed. Boca Raton: Taylor \& Francis Group, 2006. $506 \mathrm{p}$.

[5] Моро У. Микролитография. М.: Мир, 1990. Ч. 1. 605 с. Ч. 2. $632 \mathrm{c}$.

[6] Андреев В.М., Гребенщикова Е.А., Задиранов Ю.М., Ильинская Н.Д., Калиновский В.С., Малевская А.В., Усикова А.А. Патент № 2485628. 20.06.2013.

[7] Андреев В.М., Ильинская Н.Д., Калюжный Н.А., Лантратов В.М., Малевская А.В., Минтаиров С.A. Патент № 2354009. 07.12.2007.

[8] Ефимов Е.А., Ерусалимчик И.Г. Электрохимия германия и кремния. М.: Госхимиздат, 1963. $182 \mathrm{c.}$ 